\title{
Knowledge and Preventive Practices about Hepatitis B and C Virus Infection among Nursing Staffs and Paramedics in Combined Military Hospital, Dhaka
}

\author{
Hamid MA ${ }^{1}$, Chowdhury MA², Islam SMS ${ }^{3}$
}

DOI: https://doi.org/10.3329/jafmc.v16i1.53833

\begin{abstract}
Introduction: Hepatitis $B$ and $C$ virus infections are important but mostly neglected public health problem in Bangladesh, although a large number of people are suffering from that illness. It is one of the leading cause of morbidity and mortality in the country today.
\end{abstract}

Aim: To assess the level of knowledge and preventive practices regarding hepatitis $\mathrm{B}$ and $\mathrm{C}$ and to compare between the nursing staffs and paramedics in $\mathrm{CMH}$, Dhaka.

Methods: This descriptive cross sectional study was carried out among 141 respondents; 60 nurses and 81 paramedics in $\mathrm{CMH}$, Dhaka from July 2018 to December 2018. All the respondents were interviewed through an interviewer-administered questionnaire. Data were analyzed with SPSS 20. Chi-square test was used to see the level of significance.

Results: In this study, $57.4 \%$ paramedics had HSC or equivalent educational status, on the other hand among nursing staffs $39.0 \%$ had graduate or equivalent and $3.5 \%$ had masters or equivalent educational level. Knowledge and preventive practices about hepatitis $B$ and $C$ of nursing staffs was significantly $(p<0.05)$ higher than paramedics. Preventive practice was significantly $(p<0.05)$ associated with status of knowledge.

Conclusion: Overall knowledge and preventive practices were found to be acceptable in this study. Most of the nursing staffs and paramedics were at risk of hepatitis B \& C. So, appropriate measures needed for further improvement of preventive practices by nursing staffs and especially paramedics.

Key-words: Preventive practice, Hepatitis B \& C infection.

\section{Introduction}

Health care workers are more vulnerable to hepatitis B and hepatitis $C$ virus infection ${ }^{1}$. Hepatitis has become one of the major public health problem of the world with about 170 million patients are chronically infected with hepatitis $\mathrm{C}$ virus $(\mathrm{HCV})^{2}$. An estimated 240 million people are chronically infected with hepatitis $B^{3}$. Worldwide, HBV \& HCV are a major cause of chronic liver disease and liver cancer ${ }^{4}$.

In Bangladesh, hepatitis B surface antigen ( $\mathrm{HBsAg}$ ) prevalence ranges from $3-7 \%$ among the general population and $1.5-12 \%$ among children under 5 years 5 . The lifetime risk of acquiring HBV is between $20-60 \%$ in Bangladesh ${ }^{6}$. HBV is transmitted through blood or body fluids, including wound exudates, semen, vaginal secretions and saliva. Blood and serum contain the highest concentrations of the virus ${ }^{4}$. Hepatitis $B$ is a vaccine preventable disease for which a safe, immunogenic and effective vaccine is recommended since 1982 though its implementation is still insufficient ${ }^{6}$. Lack of education and knowledge regarding its spread is the main factors contributing to this disease ${ }^{7}$. Health care personnel are at increased risk of contracting blood borne pathogens due to their occupational exposure to blood and body fluids. When compared to other health personnel, the nursing staff and paramedics are the groups that are most frequently victimized by accidents with cutting and piercing objects. Thus their chance of accidental exposure to hepatitis B \& $C$ is high and they are considered as high risk group. Particularly nursing students are at a greater risk due to their limited clinical experience. Knowledge and practice of nursing students, nurses and paramedic about transmission of hepatitis $B \& C$ virus, incubation period, high risk groups, signs and symptoms of HBV and HCV and vaccination can limit the spread of disease in a large scale. Furthermore, not all hepatitis $B$ \& $C$ infections are symptomatic, meaning a person may spread hepatitis virus without knowing it. Knowledge and Practice of the health care workers plays a key role in prevention of spread of infection ${ }^{8}$. Thus this study was conducted with the objective to assess knowledge and preventive practices of nurses and paramedics regarding hepatitis $\mathrm{B}$ and $\mathrm{C}$ in $\mathrm{CMH}$, Dhaka. The finding of this study may provide some guide-lines in taking preventing measures and to make further specific study.

\section{Materials and Methods}

This descriptive cross-sectional study was conducted to assess the level of knowledge and preventive practices about hepatitis B and $C$ of nurses and paramedics and to compare between two groups in CMH, Dhaka from July 2018 to December 2018. Estimated sample size was 141 nurses and paramedics. Out of these, 60 were nurses and 81 were paramedics. The respondents who were willing to participate were included in this study. Non-probability sampling of convenient type was followed to select the respondent. The data were collected with an intervieweradministered questionnaire by face to face interview. All data were checked thoroughly after collection. Data processing and analysis

1. Lt Col Md Abdul Hamid, MBBS, MPH, Deputy Contingent Commander, BANMED-6, MINUSCA, Central African Republic (E-mail: hamid101040@gmail.com) 2. Col Mohammed Ali Chowdhury, MBBS, MPH, FCGP, MPhil Course (HMM), AFMI, Dhaka 3. Col Saleh Mohammad Shahedul Islam, MBBS, MCPS, FCPS (Medicine), FCPS (Gastroenterology), Classified Specialist in Medicine \& Gastroenterologist, CMH, Bogura. 
were done by using SPSS 20. For inferential statistics Chi-square test was done to see the level of significance and $p<0.05$ was considered to be significant. The participants were briefed properly about the objectives of the study and freedom for participating in the study. Informed written consent was obtained from the participants before data collection. All the participants were assured of complete anonymity and confidentiality.

\section{Results}

In this study, $57.4 \%$ paramedics had HSC or equivalent educational status, on the other hand among nursing staffs $39.0 \%$ had BSC or equivalent educational status and $3.5 \%$ had masters or equivalent educational. Among the respondents' female and male were $60 \%$ and $40 \%$ respectively. Table-I shows knowledge about hepatitis $B$ and $C$, where it was found that majority respondents of both group had knowledge about disease. Mean percentage of knowledge of nursing staffs and paramedics was 91.6 and 79.0 respectively. Table-II shows comparison of knowledge among study groups, where it was found that out of
141 respondents 119 of them had knowledge about hepatitis B \& C. It was also found that $91.6 \%$ nursing staffs had knowledge about disease, on the other hand $79.0 \%$ paramedics had knowledge about disease which was significantly different $(p<0.05)$. Table-III shows preventive practices about disease, where it was found that majority respondents of both group had carried out preventive practices regarding hepatitis B and C. Mean percentage of preventive practice of nursing staffs and paramedics was 81.7 and 66.7 respectively. Table-IV shows that $81.7 \%$ nursing staffs had carried out preventive practice regarding hepatitis B \& C, on the other hand $66.7 \%$ paramedics had performed preventive practice about disease which was significantly different $(p<0.05)$. Table- $V$ shows distribution of preventive practice of the respondents by their knowledge, where it was found that out of 141 respondents 119 had knowledge about disease and 22 had no knowledge. Within knowledge group $79.8 \%$ respondents had performed preventive practice and $20.2 \%$ had not carried out preventive practice about disease which was significantly different $(p<0.05)$.

Table-I: Knowledge of study participants about Hepatitis B and C ( $n=141)$

\begin{tabular}{|c|c|c|c|c|c|c|}
\hline \multirow[b]{3}{*}{ Knowledge variables } & \multicolumn{6}{|c|}{ Study Groups } \\
\hline & \multicolumn{3}{|c|}{ Nursing staffs $(\mathrm{n}=60)$} & \multicolumn{3}{|c|}{ Paramedics $(\mathrm{n}=\mathbf{8 1})$} \\
\hline & $\begin{array}{c}\text { Correct } \\
(\%)\end{array}$ & $\begin{array}{c}\text { Incorrect } \\
(\%)\end{array}$ & $\begin{array}{c}\text { Indeterminate } \\
(\%)\end{array}$ & $\begin{array}{c}\text { Correct } \\
(\%)\end{array}$ & $\begin{array}{c}\text { Incorrect } \\
(\%)\end{array}$ & $\begin{array}{c}\text { Indeterminate } \\
(\%)\end{array}$ \\
\hline \multicolumn{7}{|c|}{ Basicinformation } \\
\hline Disease & 100.0 & 0 & 0 & 100.0 & 0.0 & 0.0 \\
\hline Causative orcanism & 92.6 & 3.9 & 3.5 & 82.5 & 10.2 & 7.3 \\
\hline Site of action & 91.6 & 4.4 & 4.0 & 79.01 & 12.9 & 8.0 \\
\hline Complications & 90.6 & 5.4 & 4.0 & 75.52 & 14.2 & 10.2 \\
\hline Age of getting disease & 83.2 & 10.4 & 6.4 & 58.02 & 31.6 & 10.3 \\
\hline \multicolumn{7}{|c|}{ Mode of transmission } \\
\hline Contaminated blood & 92.3 & 4.5 & 3.2 & 81.2 & 9.0 & 9.8 \\
\hline Un-sterilized syringes & 91.8 & 5.2 & 3.0 & 80.0 & 12.0 & 8.0 \\
\hline Blades of barbers & 90.7 & 5.1 & 4.2 & 75.8 & 15.1 & 9.1 \\
\hline \multicolumn{7}{|c|}{ Vaocine availability } \\
\hline Hepatitis B & 93.2 & 4.3 & 2.5 & 80.2 & 10.7 & 9.1 \\
\hline Hepatitis C & 90.0 & 6.5 & 3.5 & 77.8 & 12.1 & 10.1 \\
\hline \multicolumn{7}{|c|}{ Treatment Availablity } \\
\hline Hepatitis B & 92.6 & 4.4 & 3.0 & 79.6 & 12.2 & 10.2 \\
\hline Hepatitis C & 90.5 & 5.2 & 4.3 & 78.2 & 12.6 & 9.2 \\
\hline Burden of disease & 917.7 & 5.2 & 3.1 & 78.5 & 11.1 & 10.4 \\
\hline Average & 91.6 & 5.0 & 3.4 & 79.0 & 12.6 & 8.4 \\
\hline
\end{tabular}

Table-II: Overall comparison of knowledge among study groups ( $n=141)$

\begin{tabular}{|l|c|c|c|}
\hline \multirow{2}{*}{ Knowledge } & \multicolumn{2}{|c|}{ Study Group (n=141) } & \multirow{2}{*}{ Total } \\
\cline { 2 - 3 } & Nursing staffs $(\mathrm{n}=00)$ & Paramedics $(\mathrm{n}=81)$ & \\
\hline Correct & $55(91.6 \%)$ & $64(79.0 \%)$ & 119 \\
\hline Incorrect/No knowledge & $5(8.4 \%)$ & $17(21.0 \%)$ & 22 \\
\hline Total & $60(100 \%)$ & $81(100 \%)$ & 141 \\
\hline Statistics & \multicolumn{2}{|c|}{$\chi^{2}=4.191, \mathrm{df}=1, \mathrm{p}<0.05$} \\
\hline
\end{tabular}


Table-III: Preventive practices of participants regarding Hepatitis B and C ( $\mathrm{n}=141)$

\begin{tabular}{|l|c|c|c|c|c|c|}
\hline \multirow{2}{*}{ Variables about preventive practice } & \multicolumn{5}{c|}{ Study Groups (n=141) } \\
\cline { 2 - 7 } & \multicolumn{3}{|c|}{ Nursing staffs (n=60) } & \multicolumn{3}{c|}{ Paramedics (81) } \\
\cline { 2 - 7 } & Yes & No & Indecisive & Yes & No & Indecisive \\
\hline $\begin{array}{l}\text { Do you use sterilized gauge, gloves, gowns, surgical } \\
\text { instruments and syringe when required? }\end{array}$ & 81.7 & 14.1 & 4.2 & 68.0 & 21.5 & 10.5 \\
\hline $\begin{array}{l}\text { Do you get the blood screened for hepatitis B and C before } \\
\text { transfusion? }\end{array}$ & 80.6 & 15.3 & 4.1 & 65.4 & 22.4 & 12.2 \\
\hline Do you practice recapping syringe after use? & 82.7 & 13.1 & 4.2 & 69.1 & 20.9 & 10.0 \\
\hline Did you screen your blood for HBV? & 79.5 & 12.5 & 8.0 & 66.7 & 23.1 & 10.2 \\
\hline $\begin{array}{l}\text { Do you turn into extra cautious during management of } \\
\text { hepatitis B \& Cpositive cases? }\end{array}$ & 84.1 & 10.8 & 5.1 & 64.5 & 20.9 & 14.6 \\
\hline $\begin{array}{l}\text { Do you share personal belongings (glass, razor and towel) } \\
\text { of others and ask barber to use new blades? }\end{array}$ & 81.6 & 11.2 & 7.2 & 66.7 & 21.1 & 12.2 \\
\hline \multicolumn{1}{|c|}{ Average } & 81.7 & 12.8 & 5.5 & 66.7 & 21.7 & 11.6 \\
\hline
\end{tabular}

Table-IV: Overall comparison of preventive practice among study groups $(n=141)$

\begin{tabular}{|c|c|c|c|}
\hline \multirow{2}{*}{ Preventive practice } & \multicolumn{2}{|c|}{ Study Group (n=141) } & \multirow{2}{*}{ Total } \\
\cline { 2 - 3 } & Nursing staffs $(\mathrm{n}=60)$ & Paramedics $(81)$ & $103(73 \%)$ \\
\hline Present & $49(81.7 \%)$ & $54(66.7 \%)$ & $38(27 \%)$ \\
\hline Absent & $11(18.3 \%)$ & $27(33.3 \%)$ & $141(100 \%)$ \\
\hline Total & $60(100 \%)$ & $81(100 \%)$ & \\
\hline Statistics & \multicolumn{2}{|c|}{$\chi^{2}=3.939, \mathrm{df}=1, \mathrm{p}<0.05$} \\
\hline
\end{tabular}

Table-V: Distribution of preventive practices of the respondents by their knowledge $(\mathrm{n}=141)$

\begin{tabular}{|c|c|c|c|}
\hline \multirow{2}{*}{ Knowledge } & \multicolumn{2}{|c|}{ Preventive practice } & \multirow{2}{*}{ Total } \\
\cline { 2 - 3 } & Present & Absent & $119(84.4 \%)$ \\
\hline Yes & $95(79.8 \%)$ & $24(20.2 \%)$ & $22(15.6 \%)$ \\
\hline No & $8(36.4 \%)$ & $14(63.6 \%)$ & $141(100 \%)$ \\
\hline Total & $103(73 \%)$ & $38(27 \%)$ & \\
\hline Statistics & \multicolumn{2}{|c|}{$\chi^{2}=17.820, \mathrm{df}=1, \mathrm{p}<0.05(0.0001)$} \\
\hline
\end{tabular}

\section{Discussion}

Hepatitis $B$ and hepatitis $C$ are major public health problems globally casting an enormous burden on health care system ${ }^{9,10}$. Hepatitis $B$ and $C$ are transmitted parentally, due to injury with contaminated sharp instruments, sharing of needles or by sexual contact and also through perinatal transmission from mother to child". These are important causes of hepatocellular carcinoma resulting in substantial morbidity and mortality ${ }^{12}$. These infections are also an important occupational hazard for Health Care Workers due to proximity to the health facility ${ }^{13}$. Knowledge and preventive practice studies are useful steps to asses extent to which an individual or community is in a position to adopt a disease risk-free behavior for this disease. Therefore, this study had been carried out with a motive to assess the knowledge and preventive practice regarding the hepatitis $B$ \& $C$ infection and help in increasing the awareness level of health Care Workers for the benefit of entire community health. In this study 91.6\% nursing staffs and $79.0 \%$ paramedics demonstrated an adequate level of knowledge about hepatitis B and C. Both group had knowledge about disease, its causative organism and about main organs involved. A high proportion in both groups knew about infectivity and communicability of these diseases by unsafe syringes, needles, contaminated blood and shared blade. Knowledge about complications due to hepatitis $B$ and $C$, non-availability of vaccine against hepatitis $C$ was found to be comparatively lower. This result is consistent with the study result of Khan et al in 2017 and Samual et a ${ }^{14}$ which was carried out in 2009. Mean percentage of knowledge of nursing staffs and paramedics was 91.6 and 79.0 respectively. This result is consistent with the study result of Khan et al ${ }^{8}$ in 2017 and Razi et al ${ }^{15}$ which had been carried out in 2010. Out of 141 respondents 119 had knowledge about hepatitis B and C. It was also found that $91.6 \%$ respondents of nursing staffs had knowledge about disease, on the other hand $79.0 \%$ respondents of paramedics had knowledge about disease which was significantly different $(p<0.05)$. Knowledge about hepatitis $B$ and $C$ of nursing staffs was significantly $(p<0.05)$ higher than paramedics. This result is 
consistent with the study result of Razi et $\mathrm{al}^{15}$ and Reddy et $\mathrm{al}^{1}$ which had been carried out in 2011. About $81.7 \%$ respondents of nursing staffs had carried out preventive practice regarding hepatitis $B \& C$, on the other hand $66.7 \%$ respondents of paramedics had performed preventive practice about disease which was significantly different $(p<0.05)$. Preventive practices regarding hepatitis $B$ and $C$ of nursing staffs was significantly $(p<0.05)$ higher than paramedics. This result is consistent with the study result of Khan et al ${ }^{8}$ which had been conducted in 2017. Out of 141 respondents 119 had knowledge about disease and 22 had no knowledge. Within knowledge group 79.8\% respondents had performed preventive practice and $20.2 \%$ had not carried out preventive practice about disease which was significantly different $(p<0.05)$. Preventive practice was significantly $(p<0.05)$ associated with the level of knowledge. The positive correlations between knowledge and practice in this study confirm the association between knowledge and practice with infection control measures. It is concluded that adequate knowledge can lead to good practices. This result is consistent with the study result of Khan et $\mathrm{al}^{8}$.

\section{Conclusion}

The existing level of knowledge and preventive practice about hepatitis $B$ and $C$ is acceptable among the nursing staffs and paramedics in $\mathrm{CMH}$, Dhaka which need to be strengthened especially in paramedics. HBV and HCV infections are serious public health problems that can causes occupational diseases, which can be transmitted from patients to health care professionals and from the professionals to their patients and may also spread to members of their family due to intimate contact. Nursing staffs and paramedics are the first level of contact between patients and medical care and always exposed to blood and blood products in their professional practice. Certainly, we should make sure the nursing staff and paramedics are kept up-to-date and very well educated regarding hepatitis $\mathrm{B}$ and $\mathrm{C}$ starting from their formal educations at the training institute. This study intends to generate some statistical information which can serve as baseline data for further in-depth study in broader perspective.

\section{References}

1. Reddy RS, Swapna LA, Ramesh T et al. Knowledge, attitude and practice on hepatitis $B$ prevention among dental professionals in India. Braz J Oral Sci 2011; 10(4):241-5.

2. WHO. Hepatitis C. World Health Organization Fact Sheet 2015:164.
3. WHO. Hepatitis: Aact sheets, 2015. Accessed online July 14, 2018. Available at http://uww.who.int/topics/ hepatitis/factsheets/en/

4. Massachusetts Department of Public Health, Bureau of Communicable Disease Control. Guide to Surveillance, Reporting and Control, 2006. Accessed online July 15, 2018. Available at http://www.mass.gov/eohhs /docs/dph/diseasereporting/guide/hepatitis-b.pdf

5. ICDDR,B. Impact of Hepatitis B vaccination programme in Bangladesh; Health and Science Bulletin 2013; 11(1):1-8.

6. Al-Mahtab M, Rahman S, Karim M. Guideline for treating hepatitis B virus infection in Bangladesh. Bangladesh Liver J 2009; 1(1):6-12.

7. Rana JS, Khan AR, Haleem A et al. Hepatitis C: Knowledge, Attitudes and Practices among Orthopedic Trainee Surgeons in Pakistan. Annals of Saudi Medicine 2000; 20(5-6):477-9.

8. Khan NR, Riya S, Islam MS et al. Knowledge and Preventive Practice Regarding Hepatitis B among the nurses in Dhaka Medical College. Journal of Dhaka Medical College 2017; 26:37-41.

9. Pokorski RJ 2006. Cost/benefit of laboratory tests. Journal of Insurance Medicine 2006; 38:31-43.

10. Wong JB. Hepatitis C: Cost of illness and considerations for the economic evaluation of antiviral therapies. Pharmacoeconomics 2006; 24:661-72.

11. Kamal GI. Pathogenic features of chronic hepatitis. Am J Clin Pathol 2000; 113:40-55.

12. Mujeeb AS, Jamal Q, Khanani $R$ et al. Prevalence of hepatitis $B$ surface antigen and HCV antibodies in hepatocellular carcinoma cases in Karachi, Pakistan. Trop Doct 1997; 27:45-6.

13. Kesieme EB, Uwakwe K, Irekpita $E$ et al. Knowledge of Hepatitis B Vaccine among Operating Room Personnel in Nigeria and Their Vaccination Status. Hepat Res Treat 2011; 2011:1570-89.

14. Samuel SO, Aderibigbe SA, Salami T et al. Health workers' knowledge, attitude and behaviour towards hepatitis $B$ infection in Southern Nigeria. Int J Med Sci 2009; 1:418-24.

15. Razi A, Rehman RU, Naz S et al. Knowledge Attitude and Practices of University Students Regarding Hepatitis B and C. ARPN J Agric Biol Sci 2010; 5(4):38-43. 